\title{
Plasma Cell Neoplasms, Clinicopathological Characteristics and Immunophenotype of 21 Patients
}

\author{
Mónica Belinda Romero-Guadarrama ${ }^{1,2^{*}}$, Cinthia Adriana Meza Medina ${ }^{3}$, Elvira Aguilar Martínez ${ }^{4}$ \\ ${ }^{1}$ Unidad de Patología del Hospital General de México, Mexico City, Mexico; ${ }^{2}$ Facultad de Medicina, Universidad Nacional \\ Autónoma de México, Mexico City, Mexico; ${ }^{3}$ Facultad de Medicina, Universidad Autónoma de Nayarit, Tepic, Mexico; ${ }^{4}$ Unidad de \\ Hematología del Hospital General de México, Mexico City, Mexico. \\ Email: *monicaromero@att.net.mx
}

Received August $9^{\text {th }}$, 2012; revised September $9^{\text {th }}$, 2012; accepted September $19^{\text {th }}, 2012$

\begin{abstract}
Introduction: Plasma cell neoplasms are monoclonal proliferations characterized by the secretion of an immunoglobulin product known as component "M" or monoclonal. The World Health Organization (WHO 2008) defines as plasma cell neoplasms the following: plasma cell myeloma, plasmacytoma and those syndromes defined by immunoglobulin deposits and primary amyloidosis, The objective of the present work was to correlate their clinical, morphological and phenotype characteristics in 21 patients. Material and Methods: A 2-year retrospective review was performed of the files of the surgical pathology laboratory and of the hematology service of the General Hospital of Mexico, searching for patients with a diagnosis of plasma cell neoplasm. We analyzed the following variables: age, gender, clinical symptoms, evolution, localization, laboratory tests, morphology, and expression of immunohistochemical markers. Of the 21 patients, $12(57.1 \%)$ corresponded to plasma cell myelomas and $9(42.8 \%)$ were plasmacytomas (seven extraosseous and two solitary bone plasmacytoma); women predominated with $61.4 \%$ and age ranged between 22 and 84 years. Mass and epistaxis were observed in the patients with plasmacytomas, and symptoms of medullary compression and anemia were observed in those patients with plasma cell myeloma. The time of symptomatology varied from 3 to 12 months. Laboratory tests revealed that lactate dehydrogenase (LDH), beta 2 microglobulin, C-reactive protein were altered and that hypercalcemia and anemia were present more in the systemic form of the disease. Treatment depended on the clinical staging and laboratory data. Mature forms predominated morphologically. Immunohistochemical stain revealed a constant expression for CD 138, six patients expressed CD 56, and expression of the Kappa and Lambda light chains was while.
\end{abstract}

Keywords: Plasma Cell Neoplasms

\section{Introduction}

Clonal proliferations of plasmatic cells and their precursors constitute a spectrum of diseases previously known as: "plasma cell dyscrasias". This group includes monoclonal gammopathy of indeterminate significance, which is characterized by the presence of low levels of paraprotein in the peripheral blood, with a variable time of evolution, and later on development of a plasma cells myeloma; this phenomenon is considered as a precursor lesion.

Other immunoglobulin secreting neoplasms that affect lymphoid and plasmatic cells lie within the current classification of WHO-2008 regarding hematolymphoid neoplasms, such as the lymphoplasmacytic lymphoma, Waldenström's macroglobulinemia, and heavy chain diseases [1].

"Corresponding author.
A myeloma is a disease of adults with an average age of 62 years, it manifests by bone pain, lithic injuries in several bones, anemia, and recurring infections. It was first described in 1844 by Dr. Samuel Solly, who assigned the name Mollities ossium to the condition [2]. Dr Bence Jones studied urine samples and described the proteins that bear his name (BJ) [3]. It was in 1873 that Rustizky described and used for the first time the term "multiple myeloma" to point out the variety of bone lesions [4].

The solitary bone plasmacytoma affects the axial skeleton and the thoracic vertebras, it is manifested by localized bone pain and medullary compression symptoms; $70 \%$ of patients present systemic symptoms after 2 to 4 years of evolution [5]. The extramedullary plasmacytoma is localized in the head and neck, gastrointestinal tract, central nervous system, skin, and other organs. In general, it does not produce detectable serum parapro- 
teins and rarely becomes disseminated. The diagnosis of solitary bone plasmacytoma or extraosseous myeloma is established after extensive imaging studies, such as MRI to exclude systemic disease. The risk of local recurrence and dissemination is high in patients with solitary bone plasmacytoma accompanied by persistence of monoclonal serum protein after local radiotheraphy [5].

The objective of this study is to present the clinical, morphological, and immunophenotype characteristics of 21 patients studied at the General Hospital of Mexico.

\section{Material and Methods}

From the archives of the Surgical Pathology and Immunohistochemistry Service of the Pathology Unit of the General Hospital of Mexico, we reviewed the slides stained with hematoxylin-eosin, periodic acid-Shiff stain and the immunohistochemical markers of 21 patients diagnosed with plasma cell neoplasms and classified them according to WHO-2008 guidelines for hematolymphoid neoplasms [1] diagnosed in a two-year period (2006 and 2007).

We identified the morphology of the plasmatic cells: mature, lymphoplasmacytic and immature or anaplastic. Strepto-avidin-biotin-peroxidase was the immunohistochemical technique used manually. The monoclonal antibodies used were: Kappa (1:1000), Lambda (1:1000), CD 138 (1:50), CD 56 (1:20), CD 20 (1:50) and CD5 (1:50) (Dako, Carpinteira, CA, USA).

Clinical information was gathered from the clinical files and we analyzed the following variables: age, gender, localization, duration of symptoms, and laboratory tests performed, anemia, lactate dehydrogenase (LDH), beta-2-microglobulin, and serum proteins. We correlated the clinical morphological variables and the immunophenotype.

\section{Results}

From the 21 patients with a diagnosis of plasma cell neoplasm, 12 were identified with having plasma cell myelomas (M) and 9 had plasmacytomas (7 extraosseous and 2 osseous) (P) (Figure 1).

The clinical data of the patients with plasma cell myeloma (57.7\%) are depicted on Table 1. Nine (75\%) were women and three $(25 \%)$ were men.

The youngest patient was a 31-year-old woman, who at the time of diagnosis presented a 38-week pregnancy. The oldest was a man of 84 years. Average age was 54.2 years. The most affected sites were the skull in six (50\%), spinal cord in 4 (33.3\%), and less frequently affected structures were bone marrow, long bones, pelvis, clavicle, palate, lymph node, and intestine.

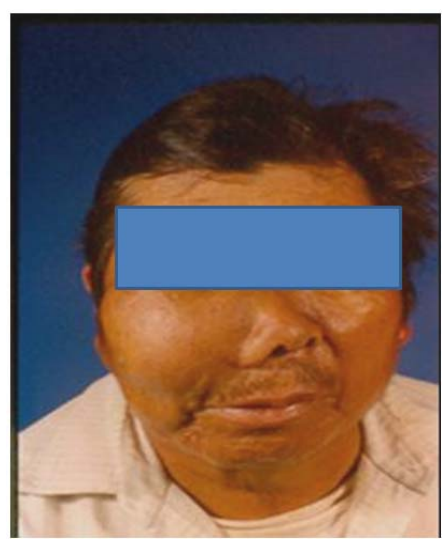

Figure 1. Plasmacytoma in the antrochoanal región.

Table 1. Clinico-pathological characteristics of patients with plasma cells myeloma.

\begin{tabular}{|c|c|c|c|c|c|c|}
\hline Case & Gender & Age & Site & Laboratory & Morphology & Inmunohistochemistry \\
\hline 1 & $\mathrm{w}$ & 42 & Skull and thorax & $\mathrm{B}-2 \mathrm{~m}$ & MPC & CD 138/Карра \\
\hline 2 & $\mathrm{~m}$ & 52 & SC T5 and T4 & Anemia, LDH & MPC & CD 138/Kappa \\
\hline 3 & $\mathrm{w}$ & 59 & Palate, skull & Anemia, LDH Sx viscocity ARF, Gammopathy & MPC & CD 138/Карра \\
\hline 4 & $\mathrm{w}$ & 65 & Skull Intestine & LN, BM, Anemia, B2-m PBJ+ & MPC & CD 138/Карра \\
\hline 6 & w & 50 & Thorax, clavicle Humer (PF) & Anemia, B-2m ARF & MPC & CD 138/Карра \\
\hline 7 & $\mathrm{w}$ & 56 & $\begin{array}{l}\text { Parietal skull BM, pain in half of } \\
\text { the face infiltrated BM }\end{array}$ & B-2m, FRA & MPC & CD 138/Lambda \\
\hline 8 & $\mathrm{w}$ & 66 & SC C T BM & PBJ+ Anemia & MPC & CD 138/Lambda CD 56+ \\
\hline 9 & $\mathrm{~m}$ & 56 & SCT Pain, paresthesias & $\mathrm{B}-2 \mathrm{~m}$ & MPC & CD 138/Lambda \\
\hline 11 & $\mathrm{w}$ & 47 & Skull and long bones & Anemia, PBJ+ B-2m & MPC & CD 138/Lambda \\
\hline 12 & $\mathrm{~m}$ & 84 & Skull and pelvis Bone pain & Anemia LDH & MPC & CD 138/Lambda \\
\hline
\end{tabular}

B-2m (Beta-2 microglobulin), LDH (Lactic dehidrogenase), ARF (Altered renal function), PBJ (Bence-Jones Protein), Preg (pregnancy) WG (weeks of gestation), MPC ( mature plasma cells), IPC (immature plasma cells), PF (pathological fracture). VC (vertebral column), BM (bone marrow), LN (lymph node). 
Seven patients (58.3\%) presented anemia, in six (50\%) 2-beta-microglobulin of more than $3.5 \mathrm{mg} / \mathrm{L}$ was found, three patients presented monoclonal gammopathy: IgG > $3.5 \mathrm{~g} / \mathrm{dL}, \mathrm{IgA}>2 \mathrm{~g} / \mathrm{dL}$, and two patients had altered renal function, one coursed with hypercalcemia and elevated LDH.

Morphologically, the neoplastic cells corresponded to mature plasmatic cells in 10 patients (83.3\%) (Figure 2) and two showed immature and pleomorphic plasmatic cells (Figure 3). The determined immunohistochemical markers are summarized in Table 1, in which expression for CD138 was observed (Figure 4); 6 patients (50\%) expressed light Kappa chain and 50\% Lambda (Figures 5 and 6 respectively). Two patients (16\%) expressed CD

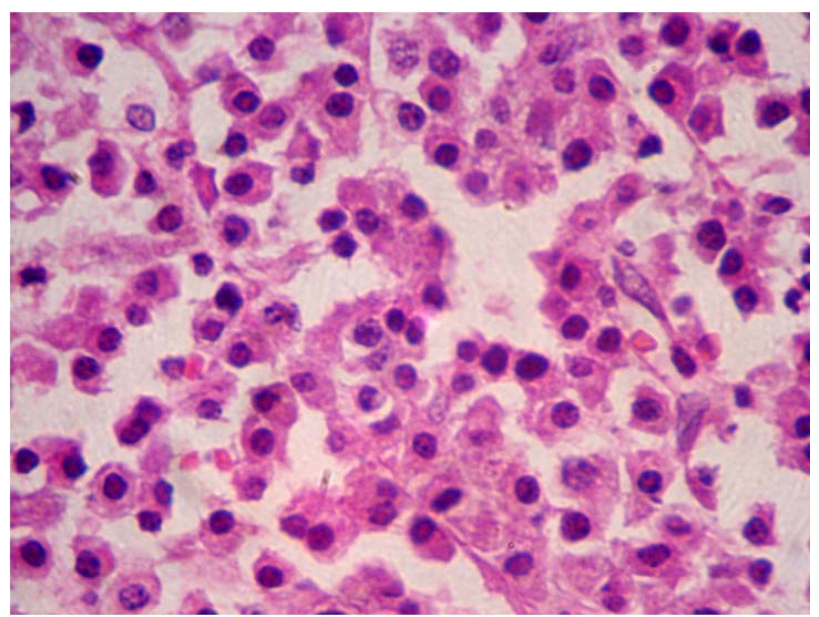

Figure 2. Mature plasma cells neoplasm (myeloma), in which cells depict and eosinophil cytoplasm and an eccentric nucleus. Some cells show cytoplasmic immunoglobulins (H-E).

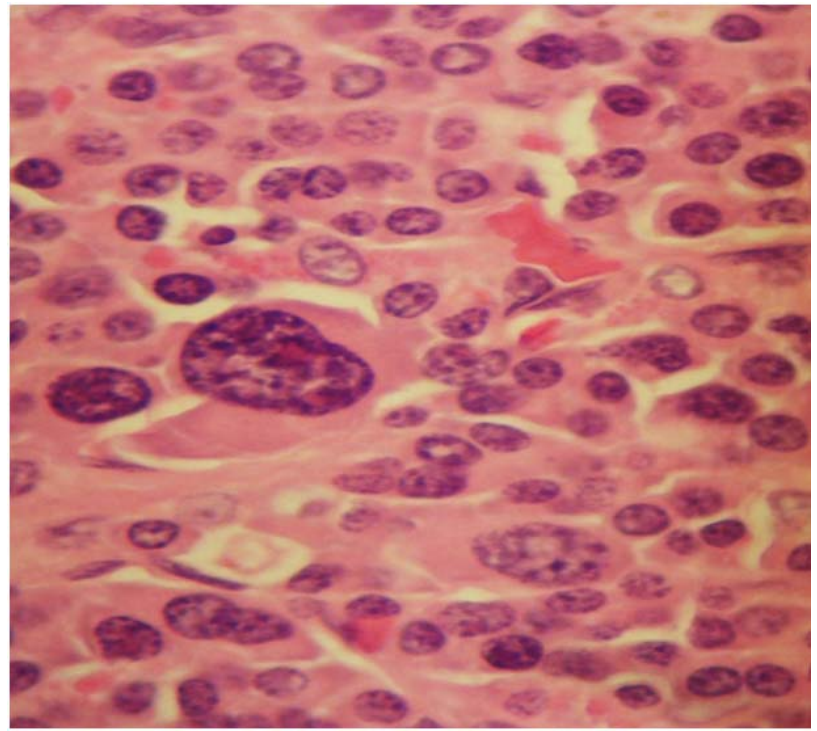

Figure 3. Plasma cells neoplasm with immature morphology. Note the pleomorphism of cells (H-E).

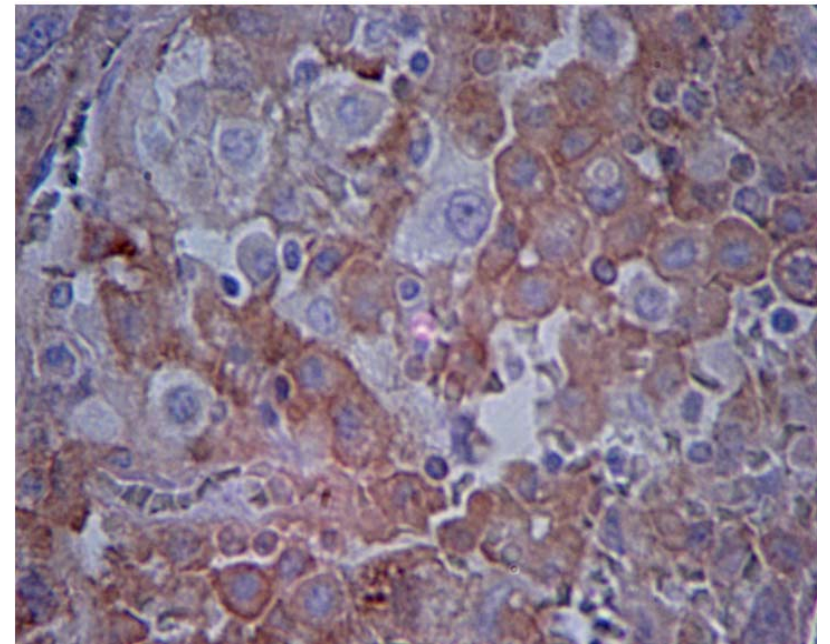

Figure 4. Inmunohistochemistry, note CD 138 expression in the cytoplasms of neoplastic plasma cells.

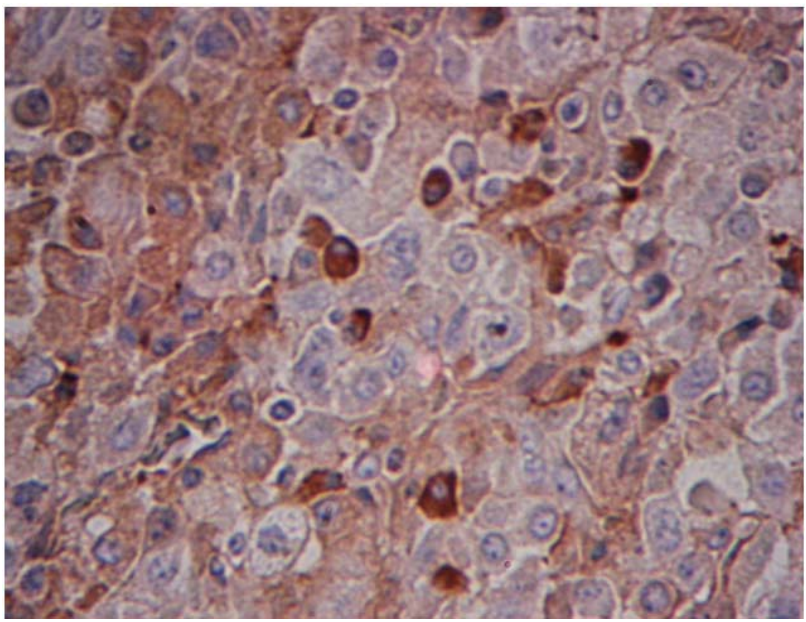

Figure 5. Lambda expression can be observed in most neoplastic cells, Immunohistochemical reaction.

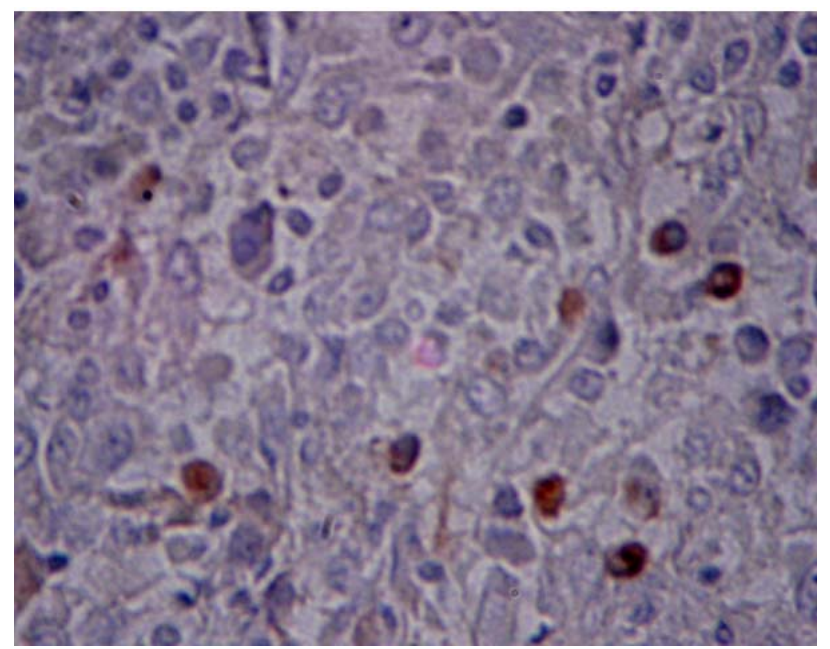

Figure 6. Note the lack of Kappa expression. Immunohistochemical reaction. 
56, which morphologically corresponded to mature plasma cells and the other presented immature cells (Table 1), The others markers such CD 20 and CD 5 were negative.

The Table 2 depicts the clinical data of patients with plasmacytomas (9 cases, 42.8\%). Seven were extraosseous (77.7\%) and two were bone (33.3\%). Four patients were men and five women, the youngest patient was a 22-year-old man without HIV antecedents and the location was in a lymph node associated to Castleman's disease, hyaline vascular type. The oldest patient was a 79-year-old patient, and the average age was of 52 years. The sites of the extraosseous plasmacytomas were: two in the nasal region and two more in the palate, and one in the following sites, anthrocoanal, gum, and cervical lymph node. The bone plasmacytomas were found in cervical vertebra and the sternum. Morphologically, seven were constituted by mature plasma cells and two revealed the presence of lymphocytes and plasmatic cells (lymphoplasmacytic variant). Immuno histochemical patterns in five expressed Kappa and two Lambda; expression for CD 56 was observed in four (44.4\%). The others markers such CD 20 and CD 5 were negative (Table 2).

\section{Discussion}

According to the compiled Histopathological Registry of 1997, plasma cell tumors occupied the 15th place and corresponded to less than $1 \%(0.4 \%)$ of the total malignnant neoplasms in our country [6].

At the Instituto Nacional de Cancerología [National Cancer Institute] in Mexico, 193 new cases of plasma cells myeloma were diagnosed between 2000-2004; of these 92 were men and 101 were women, and represented $1 \%$ of all the neoplasms diagnosed at this Institute [7].

At the General Hospital of Mexico, 21 patients were diagnosed with plasma cells neoplasm in a 2-year period, of which 12 were myelomas and 9 were plasmacytomas. In the USA, plasma cells myeloma corresponds to $1 \%$ of the total of all malignant tumors and to $10 \%$ to $15 \%$ of the hematopoietic neoplasms [8,9]. Bone and extraosseous plasmacytomas comprise $3 \%$ to $5 \%$ of plasmatic cell neoplasms in the USA [10].

The etiology is still unknown; however, they have been related with chronic antigenic stimulation due to infection, or with the exposure to specific toxic substances or radiation [11]. Ries et al. observed that plasma cells myeloma, bone and extraosseous plasmacytoma are more common in men than in women [9]. According to Rizo et al. [7] from the Instituto Nacional de Cancerología, and our results women predominate, as can be observed in Tables 1 and 2. The average age for myelomas was of 54 years, and 52 years for plasmacytomas. In the Western literature the average age for myeloma patients is 70 years, and 55 years for plasmacytomas [1].

The clinical presentation of plasma cells myeloma varies [12] and occasionally the symptomatic diagnosis is delayed several months; the main bone symptoms are lumbar pain or fractures of the affected bones. In the present work, pain was the predominant symptom in myeloma (Table 1), renal failure results from the tubular damage caused by the proteinuria of the monoclonal light chain proteins. One patient presented altered renal function and gammopathy, and in another it was not associated with gammopathy. Fractures were found in two patients. Among the altered laboratory tests, in the systemic form of the disease, we found anemia, hypercalcemia (>12 mg/dL), hyperviscocity, monoclonal peak as revealed by protein electrophoresis, protein $C$ reactive, and elevation of LDH. Anemia was the most frequent alteration found in both the study performed by Kyle in the Mayo Clinic with 1027 patients (67\% of patients with anemia) and in this study with a similar percentage of affectation (66.6\%). The presence of anemia in patients

Table 2. Clinicopathological characteristics of extraosseus and osseus plasmacytomas.

\begin{tabular}{ccclcc}
\hline Case & Gender & Age & Site & Morphology & Inmunohistochemistry \\
\hline 1 & $\mathrm{~m}$ & 49 & gum/tumor & MPC & CD 138/Kappa \\
2 & $\mathrm{~m}$ & 54 & nasal/epistaxis & MPC & CD 138/Kappa CD 56 \\
3 & $\mathrm{w}$ & 75 & palate/tumor & MPC & CD 138/Lambda \\
4 & w & 63 & nasal/epistaxis & MPC & CD 138/Kappa CD 56 \\
5 & m & 84 & antrochoanal/tumor & MPC & CD 138/Kappa \\
6 & w & 79 & palate/lymphoplasmatic infiltration & MPC & CD 138/Lambda \\
7 & w & 57 & sternun/tumor & MPC & CD 138/Kappa CD 56 \\
8 & w & 57 & SC & MPC & CD 138/Kappa CD 56 \\
9 & m & 22 & GL & MPC & CD 138/Lambda \\
\hline
\end{tabular}

MPC (mature plasmatic cells). No laboratory tests alterations were observed in any patient. CD 20 and CD 5 were negative in neoplastic plasma cells. 
results first by the replacement of bone marrow by neoplastic plasma cells and/or because of renal damage resulting from the loss of erythropoietin [13]. The other laboratory alteration found in this series was the elevation of beta-2-microglobulin in serum, which is used as a survival marker, if it is higher than $5.5 \mathrm{mg} / \mathrm{dL}$, patient's survival is reduced to only 28 months; therefore, it is an important prognostic laboratory marker [14].

Clinical variants of plasma cells myeloma include the smoldering plasma cells myeloma, in which the patients course with stable disease for long periods of time, it presents with solitary plasmacytoma with bone abnormalities detected only through Magnetic Resonance Image (MRI) and only $10 \%-20 \%$ of plasmatic cells are seen in the bone marrow [1].

Another variant is the non-secreting myeloma that corresponds to $3 \%$ of plasmatic cells myeloma. There is lack of protein $\mathrm{M}$ as assessed through fixation electrophoresis. [10] Leukemia of plasmatic cells is characterized by an increase in the number of clonal plasmatic cells in peripheral blood and exceeds $2 \times 10 / \mathrm{L},\left(2 \times 10^{9} / \mathrm{L}\right.$, $)$ or when the neoplastic plasma cells are encountered in extra-medullary sites, such as the spleen, liver, pleural fluid, ascites, and cerebrospinal fluid; it can associate seconddarily to a plasmatic cells myeloma during the course of the disease, [1] we did not identify any such case in our study. In 2006, 10 patients of the Instituto Nacional de la Nutrición y Ciencias Médicas [National Institute of Nutrition and Medical Sciences] were reported with a fulminant clinical condition, the average age of the patients was 58 years and again women predominated [15].

By definition, extraosseous plasmacytomas are located in tissues outside the bone; in the present study, the most affected site was the upper respiratory tract including the oropharynx. The plasmacytoma in the lymph node occurred adjacent to hyaline-vesicular type Castleman's disease. Bone plasmacytoma was found one in the spinal cord and the other in the sternum. Histologically, the mature plasma cells predominated in the myelomas, their arrangement in the bone marrow is in groups interstitially, and when the bone marrow is not completely substituted normal hematopoietic elements can be observed; hence, it is important to use markers such as CD 138 or CD 79a, and light immunoglobulins to discard the disease. It is important to consider the percentage of plasmatic cells in the bone marrow that should be at least of $30 \%$; another observed change is osteoclastic activity [16].

Histologically, we observed an almost complete substitution of the normal bone marrow elements by abundant plasmatic cells and CD 138 expression was almost $100 \%$, expression for Kappa and Lambda light chains was the same. CD 56 is expressed aberrantly en plasma cells myeloma up to $70 \%$ [17]. In the present review, this marker was only expressed in two cases, one with a morphology of mature plasmatic cells and the other with immature plasma cells.

Aside from CD 56 other markers have been expressed, such as CD 117, CD 20, and CD 10; in contrast to plasmatic cells myeloma, expression of CD 56 is negative in plasmatic cells leukemia [18].

In plasmacytomas, mature morphology was observed in seven patients, and two showed lymphoplasmacytic morphology; expression of CD 56 was observed in four cases, three with mature morphology and one with lymphoplasmacytic morphology.

Expression of CD 20 favors the diagnosis of infiltration due to lymphoma, hence it must be taken into account for the differential diagnosis. The immunophenotype of this form of plasmatic cells neoplasm has not been studied extensively, but apparently it is similar to the myeloma phenotype. Expression of CD 56 was observed more frequently in this form, however, more studies have to be made, because probably this last marker could be used as a prognostic marker in the future.

Although diverse genetic anomalies have been observed through fluorescence in situ hybridization (FISH), such as in (13q14), hyperdiploidia, t (11; 14), among others; however, the most frequent translocation in plasmatic cells myeloma is the one affecting chromosome $14 q 23$ with a $70 \%$ frequency [19]. It is noteworthy, that patients with myeloma associated to translocation $t$ (11; 14) (q13; q32) are usually positive to cyclin D-1 and are associated with lymphoplasmacytic morphology with extensive infiltration to the bone marrow. In this work, only two cases presented this morphology and positivity to cyclin D-1 in the cytoplasm of the cells and not in the nucleus [20,21]. In plasmacytomas, the expression of Kappa and Lambda is very important to demonstrate clonality and to confirm the diagnosis. There are reports in the literature on the frequency of CD 56 expression and the prognostic of the patients with myeloma, which, as well known, is a marker of NK cells and of some T cell subpopulations [22].

In conclusion, we observed that the myeloma and the localized form, the extramedullary plasmacytoma, are the most frequent. The average age of patients for the myeloma group was of 54.2 year in this series and, in patients studied in two other national institutions, the age was below 60 years, that is, 15 years younger than that reported for American patients. Myeloma and another plasma cell neoplasms are not found in children and is rare in adults younger than 35 years. In our milieu, women are more affected.

Morphologically, the presence of mature plasmatic cells predominated in both types of disease, and CD 56 expression was observed in the localized form of the disease. 


\section{REFERENCES}

[1] S. H. Swerdlow, E. Campo, N. L. Harris, E. S. Jaffe, S. A. Pileri, H. Stein, J. Thiele and J. W. Vardiman, "WHO Classification of Tumours of Haematopoietic and Lymphoid Tissues," International Agency for Research on Cancer (IARC), Lyon, 2008.

[2] S. Solly, "Remarks on the Pathology of Mollities Ossium: With Cases,” Medico-Chirurgical Transactions, Vol. 27, 1844, pp. 435-461.

[3] H. B. Jones, "On a New Substance Occurring in the Urine of a Patient with Mollities and Fragilitas Ossium," Philosophical Transactions of the Royal Society of London, Vol. 1, 1848, p. 673.

[4] V. Rusitzky, "Multiples Myelom,” Dtsch Z Chir, Vol. 3, 1873, pp. 162-172.

[5] R. Soutar, H. Lucraft, G. Jackson, et al., "Guidelines on the Diagnosis and Management of Solitary Plasmacytoma of Bone and Solitary Extramedullary Plasmacytoma," British Journal of Haematology, Vol. 124, No. 6, 2004, pp. 717-726.

[6] R. Tapia-Conyer, P. Kuri-Morales, C. Macías Martínez, et al., "Registro Histopatológico de Neoplasias en México," 2012.

http//www.dgepi.salud.go.mx/infoepi/Manual/Man18-Ne oplasia/Man18.htm

[7] R. P. Rizo, M. I. Sierra, P. G. Vázquez, et al., "Registro Hospitalario de Cáncer: Compendio de Cáncer 20002004,” Cancerología, Vol. 2, No. 3, 2007, pp. 203-287.

[8] A. Jemal, R. Siegel, E. Ward, T. Murray, J. Xu and M. J. Thum, "Cancer Statistics," Cancer Journal for Clinicians, Vol. 57, No. 1, 2007, pp. 43-66.

[9] L. A. Ries, et al, Eds., "SEER Cancer Statistics Review 1975-2001,” National Cancer Institute, Bethesda, 2004.

[10] Annon, "Criteria for the Classification of Monoclonal Gammopathies, Multiple Myeloma and Related Disorders: A Report of the International Myeloma Working Group," British Journal of Haematology, Vol. 121, No. 5, 2003, pp. 749-757.

[11] M. S. Linet, S. D. Harlow and J. K. McLaughlin, "A Case-Control Study of Multiple Myeloma in Whites; Chronic Antigenic Stimulation, Occupation and Drug Use,” Cancer Research, Vol. 47, No. 11, 1987, pp. 29782981.

[12] J. Malpas, D. Bergsagel, R. Kyle and K. Anderson, Eds., "Myeloma, Biology and Management Saunders: Philadelphia,” 3rd Edition, 2004, pp. 121-143.

\footnotetext{
Abbreviations

WHO $=$ World Health Organization .

MRI = Magnetic Resonance Imagen

B-2m = Beta-2 microglobulin

LDH $=$ Lactic Dehydrogenase

ARF $=$ Altered Renal Function

PBJ = Bence-Jones Protein

Preg $=$ Pregnancy
}

[13] R. A. Kyle, M. A. Gertz, T. E. Witzig, J. A. Lust, M. Q. Lacy, A. Dispenzieri, R. Fonseca, et al., "Review of 1027 Patients with Newly Diagnosed Multiple Myeloma," Mayo Clinic Proceedings, Vol. 78, No. 1, 2003, pp. 21-33.

[14] E. E. C. Ceballos, J. E. C. Franco, J. R. E. Zamora and J. R. L. Méndez, "Oncologists Clinical of Iberoamerica. Hemato-Oncology. Part I,” Planeation and Development Editorial, S.A. of C.V., 2009, pp. 82-84.

[15] V. H. J. Zepeda, V. J. Domínguez, "Plasma Cell Leukemia: A Rare Condition,” Annals of Hematology, Vol. 85, No. 4, 2006, pp. 263-267. doi:10.1007/s00277-005-0054-4

[16] R. D. Brunning and R. W. McKenna, "Plasma Cell Dyscrasias and Related Disorders in: Atlas or Tumor Pathology,” Armed Forces Institute of Pathology, Washington, 1994

[17] P. Lin, R. Owens, G. Tricot and C. S. Wilson, "Flow Cytometric Immunophenotypic Analysis of 306 Cases of Multiple Myeloma," American Journal of Clinical Pathology, Vol. 121, No. 4, 2004, pp. 482-488.

[18] N. Sahara, A. Takeshita, K. Shigeno, S. Fujisawa, K. Takeshita, et al., "Clinicopathological and Prognostic Characteristics of CD56 Negative Multiple Myeloma," British Journal of Hematology, Vol. 117, No. 4, 2002, pp. 882-885.

[19] R. Königsberg, N. Zojer, J. Ackerman, E. Krömer, H. Kittler, E. Fritz, et al., "Predictive Role of Interphase Cytogenetics for Survival of Patients with Multiple Myeloma,” Journal of Clinical Oncology, Vol. 18, No. 4, 2000, pp. 804-812.

[20] R. Fonseca, E. A. Blood, M. M. Oken, R. A. Kyle, G. W. Dewald, R. J. Bailey et al., "Myeloma and the $\mathrm{t}(11 ; 14)$ (q13; q32); Evidence for a Biologically Defined Unique Subset of Patients,” Blood, Vol. 99, No. 10, 2002, pp. 3735-3741.

[21] J. D. Hoyer, C. A. Hanson, R. Fonseca, P. R. Greipp, G. Dewald and P. J. Kurtin, “The (11; 14) (q13; q32) Translocation in Multiple Myeloma," American Journal of Clinical Pathology, Vol. 113, No. 6, 2000, pp. 831-837.

[22] H. Chang, S. Samiee and Q. L. Yi, "Prognostic Relevance of CD56 Expression in Multiple Myeloma: A Study Including 107 Cases Treated with High-Dose MelphalanBased Chemotherapy and Autologous Stem Cell Transplant,” Leukemia \& Lymphoma, Vol. 47, No. 1, 2006, pp. 43-47. doi:10.1080/10428190500272549.

WG $=$ Weeks of Gestation

MPC = Mature Plasma Cells

IPC = Immature Plasma Cells

$\mathrm{PF}=$ Pathological Fracture

$\mathrm{VC}=$ Vertebral Column

$\mathrm{BM}=$ Bone Marrow

LN = Lymph Node 